\title{
El avatar: un modo de ser cibernético cualitativamente estacionario
}

\author{
Avatars: A Qualitatively Stationary Cybernetic Way of Being
}

O avatar: um modo de ser cibernético qualitativamente estacionário

\author{
Clara Inés Jaramillo Gaviria ${ }^{1}$ \\ José Miguel Cabarcas Bolaños ${ }^{2}$ \\ Miguel Ángel Villamil Pineda ${ }^{3}$ \\ Rubén Darío Vallejo Molina ${ }^{4}$ \\ Wilson Hernando Soto Urrea ${ }^{5}$
}

\section{Resumen}

El propósito de este artículo de investigación es presentar algunas líneas críticas sobre la ontología que sirve de base a la sociedad cibernética. Para ello, partimos de las siguientes preguntas: ¿Cuáles son las características del modo de ser cibernético?; ¿cuáles son los encuentros y desencuentros entre el avatar, en cuanto modo de ser cibernético, y la persona, en cuanto modo de ser humanista? Las tesis que intentamos defender son: a) el hombre cibernético es un avatar que desarrolla un modo de ser que se desenvuelve en el seno de una realidad digital cuantificable; b) el avatarpresupone una ontología en la que solo adquiere consistencia de realidad aquello que es reductible a operaciones digitales entre ceros y unos; c) en dicha ontología digital cuantificable los fenómenos cualitativos no tienen lugar o son simulados por el avatar, lo cual propicia el desarrollo de un modo de ser estacionario que compromete la salud de potencias cualitativas como: problemáticas, valorativas y vocacionales. Para el desarrollo de estas tesis planteamos la siguiente estructura: en primer lugar, presentamos algunos elementos clave de la ontología cibernética; en segundo lugar, analizamos los rasgos constitutivos del "avatar" en cuanto tipo de subjetividad cibernética; en tercer lugar, caracterizamos el "avatar" como un modo de ser impersonal y cualitativamente estacionario; finalmente, concluimos que la ontología cibernética tiende a constituir una sociedad "avatar" que restringe el carácter cualitativo de las personas y del mundo.

\section{Palabras clave}

modo de ser cibernético; avatar; cibernética; realidad cualitativa; realidad cuantitativa

\section{Abstract}

The purpose of this research paper is to review the ontology that serves as the basis for cybernetic society. For that purpose, we start with the following questions: What are the features of the cybernetic way of being? What are the agreements and disagreements between the avatar as a cybernetic way of being and the person as a humanistic way of being? Our theses are: a) the cybernetic man is an avatar that develops a way of being that unfolds in a quantifiable digital reality; b) the avatar presupposes an ontology in which only that which is reducible to digital operations between ones and zeros acquires reality consistency; c) in said quantifiable digital ontology, the qualitative phenomena do not take place or are simulated by the avatar, which promotes the development of a stationary way of being that compromises the health of qualitative powers such as: problematic, valuable and vocational. To develop this thesis, we propose the following structure: first, we present some key elements of cybernetic ontology; after that, we analyze the constitutive features of the "avatar" as a type of cybernetic subjectivity; then, we characterize the "avatar" as an impersonal and qualitatively stationary way of being; finally, we conclude that cybernetic ontology tends to constitute an "avatar" society that restricts the qualitative character of people and the world.

1 Doctoranda en Educación en Mediación Pedagógica de la Universidad de la Salle de Costa Rica; magíster en Educación de la Universidad Santo Tomás. Correo electrónico: clara jaramillo@usantotomas.edu.co

2 Doctor de la Facultad de Ciencias Exactas de la Universidad Nacional de La Plata. Físico de la Universidad Nacional de Colombia. Ha publicado artículos en revistas indexadas.

3 Doctor en Filosofía de la Pontificia Universidad Javeriana de Bogotá, Colombia. Profesor investigador del Departamento de Humanidades y Formación Integral de la Universidad Santo Tomás (Colombia). Correo electrónico: josecabarcas@usantotomas.edu.co

4 Doctor en Educación en Mediación Pedagógica de la Universidad de la Salle de Costa Rica; magíster en Educación de la Universidad Santo Tomás. Correo electrónico rubenvallejo@usantotomas.edu.co

5 Doctor y magíster en Educación de la Universidad Pedagógica Nacional, e ingeniero mecánico de la Universidad Nacional de Colombia. Profesor investigador del Departamento de Humanidades y Formación Integral de la Universidad Santo Tomás (Colombia).

Correo electrónico: wilsonsoto@usantotomas.edu.co 


\section{Keywords}

cybernetic way of being; avatar; cybernetics; qualitative reality; quantitative reality.

\section{Resumo}

0 propósito deste artigo de pesquisa é apresentar algumas linhas críticas sobre a ontologia na que se baseia a sociedade cibernética. Para isso, partimos das seguintes perguntas: quais são as características do modo de ser cibernético?; quais os encontros e desencontros entre o avatar, em relação ao modo de ser cibernético, e a pessoa, em relação ao modo de ser humanista? As teses que tentamos sustentar são: a) o homem cibernético é um avatar que desenvolve um modo de ser que atua no seio de uma realidade quantificável; b) o avatar pressupõe uma ontologia na que só adquire consistência de realidade aquilo que é irredutível a operações digitais entre zeros e uns; c) nessa ontologia digital quantificável, os fenômenos qualitativos não existem ou são simulados pelo avatar, o que permite o desenvolvimento de um modo de ser estacionário que envolve a saúde das potências qualitativas como são: problemáticas, valorativas e vocacionais. Para o desenvolvimento dessas teses, estabelecemos a seguinte estrutura: em primeiro lugar, apresentamos alguns elementos chave da ontologia cibernética; em segundo lugar, analisamos as características constitutivas do avatar como tipo de subjetividade cibernética; em terceiro lugar, caraterizamos o avatar como modo de ser impessoal e qualitativamente estacionário; finalmente, concluímos que a antologia cibernética visa construir uma sociedade avatar que restringe 0 caráter qualitativo das pessoas e do mundo.

\section{Palavras-chave}

modo de ser cibernético; avatar; cibernética; realidade qualitativa; realidade quantitativa.

\section{Artículo recibido el 10 de mayo de 2017 y aprobado el 10 de enero de 2018}

\section{Introducción}

Este artículo es resultado del proyecto de investigación "Emociones y conflictos en el cultivo de la paz", código 17352010, aprobado por la Unidad de Investigación para el Fomento y Desarrollo de la Investigación de alto nivel de la Universidad Santo Tomás (Fodein), realizado interdisciplinariamente entre los grupos de investigación Aletheia, del Departamento de Humanidades y Formación Integral; y Antón de Montesinos, de la Facultad de Filosofía.

Nuestro grupo de investigación, acorde con los planteamientos de Sáez (2009; 2015), viene reflexionando sobre la sociedad estacionaria en el mundo contemporáneo. Dado que la cibernética constituye uno de los pilares de este, consideramos conveniente abordar, desde una perspectiva crítica, las relaciones entre la subjetividad cibernética en el marco de la paz.

Para el desarrollo de este artículo planteamos la siguiente estructura: en primer lugar, presentamos la física azarosa como el modo de ontología que adopta la cibernética. En segundo lugar, presentamos el avatar como el tipo de subjetividad que se constituye en la sociedad cibernética. En tercer lugar, indicamos que este avatar reproduce un modo de ser cuantitativo y estacionario que sesga el dinamismo cualitativo y errático de las personas, el cual se caracteriza por ser problemático, valorativo y vocacional.

\section{La física azarosa como el modo de ontología que adopta la cibernética}

El tema de este apartado es la ontología cibernética. Su propósito es analizar las relaciones que establece la cibernética entre la realidad, la matemática probabilística y las nuevas tecnologías de la información.

La actual sociedad del avatar, la sociedad cibernética, que tuvo sus orígenes en la Segunda Guerra Mundial, tiene como uno de sus principales teóricos y constructores a un insigne desconocido: Norbert Wiener (1894-1964). Sin embargo, su legado, aunque olvidado, vive soterradamente, aunque hoy no se encuentra oculto, basta recordar que al utilizar el prefijo ciber- necesariamente estamos inmersos en su obra cibernética (Soto, 2010).

El inspirador de la nueva sociedad y del "hombre nuevo" que la habitaría es un matemático norteamericano, Norbert Wiener... A pesar de su importancia, la influencia que tuvo en nuestra modernidad no es muy conocida. ¿Quién dentro del gran público, oyó realmente hablar de él? (Breton, 2000, p. 12). 
Nobert Wiener, en 1920, inventó una computadora analógica capaz de realizar operaciones entre integrales, se le llamó el integrafo de Wiener. En 1940, propuso la construcción de una computadora que fuera digital, que tuviera lenguaje binario, la arquitectura de una máquina de Turing, electrónica y almacenamiento de datos en una cinta magnética. Afirma Heims (1986) que la inventiva de Wiener fue muy fructífera pues no solo se destacan sus aportes en el campo de la matemática, sino también sus aportes en la ingeniería, por ejemplo, en el diseño de cañones de guerra con mayor alcance y que posteriormente le permitirían concebir el concepto de feedback (retroalimentación); adicionalmente, en las telecomunicaciones realizó una teoría estadística de la comunicación fundamental para el diseño de sistemas de comunicación telefónicos, satelitales o informáticos, esta teoría permitiría implementar los filtros Wiener que ayudan a disminuir el ruido en los equipos de comunicación.

[Norbert Wiener] contribuyó a poner en marcha lo que se ha dado en llamar la segunda revolución industrial, marcada por el desarrollo y la aplicación generalizada de nuevas tecnologías en el terreno de la comunicación y el proceso de datos. (Heims, 1995, p. 11).

En 1948, Norbert Wiener publicó Cibernética o control y comunicación en máquinas $y$ animales, libro que describiría los postulados fundamentales de la cibernética en la base de la naciente ciencia, escrito por este destacado matemático. Gifreu (2013) afirma que esta obra inaugura una ciencia multidisciplinar que se presenta como paradigma científico para analizar como sistemas los procesos en animales y máquinas; sistemas que podrían ser homogéneos entre sí y que son dependientes del control de la información y la comunicación.

Es propósito de la cibernética desarrollar una lengua y unas técnicas que nos permitan, no solo encarar los problemas más generales de comunicación y regulación, sino además establecer un repertorio adecuado de ideas y métodos para clasificar sus manifestaciones particulares por conceptos. (Wiener, 1958, p. 16).

Norbert Wiener junto al ingeniero Julián Bigelow y el cardiólogo Arturo Rosenblueth publicaron en 1943 el artículo "Behavior, purpose and teleology" en la prestigiosa revista Phylosophy of Science; el cual conceptualizaba las enunciaciones fundantes de la cibernética; es decir, la conducta, el propósito y la teleología. Estas enunciaciones permitían un análisis de los fenómenos, a partir de descripciones energéticas, informativas y comunicativas (George y Johnson, 1985). Así mismo, esta publicación permitió la legitimización del discurso comparativo entre seres humanos, animales y máquinas (Breton, 1989).

En los años futuros, con el aumento del conocimiento de los coloides y de las proteínas, los ingenieros futuros pueden procurar el diseño de robots no solamente con un comportamiento, sino también con una estructura similar de un mamífero. El último modelo de un gato es por supuesto otro gato, aunque haya nacido de otro gato o sintetizado en un laboratorio. (Rosenblueth, Wiener y Bigelow, 1943, p. 22).

La naciente cibernética toma como base la lógica matemática y el cambio de paradigma en la física. La matemática reduce a una tarea algorítmica las operaciones básicas del cálculo infinitesimal; entendiendo por algoritmo una sucesión ordenada de operaciones básicas, que son parte de un número finito de operaciones ejecutables en un tiempo determinado (Mattelart, 2002).

La matemática desarrollada por Leibniz reduce a una tarea algorítmica las operaciones básicas del cálculo infinitesimal; entendiendo por algoritmo una sucesión ordenada de operaciones básicas que son parte de un número finito de operaciones ejecutables en un tiempo determinado (Jolley, 2005). Como señalan Kasner y Newman (2007), las matemáticas pueden crear orden entre el desorden. Por esta razón, la matemática se convirtió en un fundamento epistemológico de la ciencia cibernética lo que exige que se haga un acercamiento a la lógica.

A principios del siglo xx se creía que la labor de los futuros profesionales de la ciencia física sería 
encontrar más decimales a las constantes que dieran una mayor exactitud a las leyes formuladas de la física newtoniana. Física que explicaba el universo como un todo ordenado, en donde los eventos futuros eran condicionados irremediablemente por los eventos pasados. Sin embargo, el trabajo del físico Willard Gibss permitió introducir la probabilidad a la física lo cual cambió el paradigma en esta ciencia.

La física ya no se ocupa de lo ocurrirá siempre, sino más bien de lo que ocurrirá con una probabilidad muy grande. [...] La teoría de Gibbs era esencialmente nueva, pero los casos posibles eran los mismos que los considerados por Newton. Desde entonces, se ha descartado o modificado la base newtoniana y la contingencia de Gibbs es hoy, en toda su desnudez, la verdadera base de la física. (Wiener, 1958, p. 12).

Es decir, desde comienzos del siglo $\mathrm{xx}$ se considera que el universo es una realidad entrópica y probabilística que tiende a aumentar su desorden con el transcurso del tiempo, en oposición al pensamiento newtoniano que concibe al universo como una realidad determinada y organizada. Entonces la física ya no trata de encontrar leyes que expliquen un universo ordenado, sino se busca crear espacios de orden dentro de un universo en desorden.

En el universo de Gibbs el orden es menos probable, el caos más probable. Pero mientras el universo en su totalidad, si existe en cuanto total, tiende a ese estado definitivo, existen enclavados locales, cuya dirección parece opuesta a la del universo como un todo en los cuales hay una tendencia temporal y limitada a aumentar la complejidad de su organización. La vida encuentra asilo en algunos de esos enclavados. Ligada instintivamente a esa idea desde un principio, se inicia el desarrollo de la nueva ciencia: la cibernética. (Wiener, 1958, p. 14).

En 1948, la nueva ciencia cibernética se asumió como la teoría de la información, el control y la comunicación en animales y máquinas (Wiener, 1998). En este sentido, Wiener (1958) definió la noción de información como: "el contenido de lo que es objeto de intercambio con el mundo externo" (p. 31). Esta información constituye el mensaje, el cual puede ser descrito, clasificado y anticipado de acuerdo con cálculos probabilísticos:

El mensaje es una secuencia discreta o continua de episodios mensurables distribuidos en el tiempo, lo que en estadística se denominan series temporales. La predicción del futuro de un mensaje la realiza cierta clase de operador sobre el pasado, independientemente de que dicho operador lo integre un esquema de computación matemática o un aparato mecánico o eléctrico. (Wiener, 1998, p. 31).

El control y la regulación cibernética se convirtieron en elementos clave de una concepción fundamental: primero, porque comienza a darse un acercamiento entre la biología y la mecánica, que proporcionó los fundamentos para estudios posteriores de robótica, nanotecnología, redes neuronales, entre otros; segundo, porque dio el punto de partida de la comparación que se ha hecho entre el animal humano y la máquina, entre inteligencia humana y la inteligencia artificial, entre el cerebro y el ordenador, que han llevado al desarrollo de la automatización.

La cibernética, rompió con el concepto de linealidad. En esta ciencia no existe la idea de un principio y un fin. Por el contrario, hay un eterno retorno, un ciclo circular al que se accede por medio del feedback o retroalimentación que es la capacidad de respuesta óptima para mantener regulado el ciclo de funcionamiento del sistema. Es necesaria para mantener el estado de equilibrio del sistema. Al respecto, Wiener plantea lo siguiente:

Un factor sumamente importante en la actividad voluntaria es lo que los ingenieros de control denominan feedback (retroalimentación). Cuando deseamos que un movimiento siga un patrón determinado, la diferencia entre este patrón y el movimiento realmente efectuado se utiliza como nuevo impulso para que la parte regulada se mueva de tal modo que su movimiento se aproxime más al previsto por el patrón. (1998, p. 29).

De acuerdo con lo anterior, se estructura la teoría matemática de la comunicación propuesta por Claude Shannon en 1948, donde el problema fundamental de la comunicación es reproducir fiel y 
rápidamente un mensaje seleccionado en otro punto. Con frecuencia los mensajes tienen un significado, es decir, se refieren o se relacionan según el contexto; no obstante, estos aspectos semánticos de la comunicación son irrelevantes, pues lo que importa es la cantidad de la información que debe ser medida de manera logarítmica (Otero, 2004).

Bajo estas premisas, se estructuró el sistema de comunicación a partir de la secuencia ordenada de cinco partes esenciales, a saber: a) la fuente de información que produce un mensaje o una secuencia de mensajes que se comunicarán al receptor; b) el transmisor que opera de alguna manera en el mensaje para producir una señal adecuada para la transmisión a través del canal; c) el canal que es el medio utilizado para transmitir la señal desde el transmisor al receptor; d) el receptor que realiza la operación inversa del transmisor, es decir, la reconstrucción del mensaje de la señal; e) el destino que es la persona (o cosa) para quien el mensaje se dirige (Shannon, 1948).

En esta teoría, un mensaje es igual a su cantidad de información. A su vez, la cantidad de información contenida en un mensaje es definida y medible a partir del concepto de entropía, que se presenta en el canal de comunicación en forma de ruido y la utilización del álgebra binaria (uno y cero), que no permite estados intermedios, existe o no existe información. En cuanto a la recepción de un mensaje, que forma parte de un conjunto de mensajes posibles, se calcula probabilísticamente. El valor más alto se le asigna al mensaje que menos probabilidades tiene de ser recibido, para asegurar que la información llegue a su destino, pero teniendo en cuenta que la información que se envía nunca llega en su totalidad (Kline, 2015).

En definitiva, la teoría matemática de la comunicación permite optimizar los canales de comunicación sin detrimento de la cantidad de información que se envía del emisor al receptor. Pero no se ocupa de los procesos intermedios de la información:

[...] la teoría de la información se ocupa de los hechos ocurridos entre una fuente de señales y un receptor, pero no de la naturaleza de estos térmi- nos en sí mismos, ni de las condiciones en que las señales transmitidas entre ellos se convierten en información significativa. (Buckley, 1993, p. 142).

Estas teorías se desarrollan paralelamente con la tecnología, especialmente la que corresponde al ordenador. Este artefacto facilitó las operaciones matemáticas de los científicos y permitió sentar los principios de hardware y software. Además, proporcionó una máquina de mayor eficiencia y eficacia, capaz de simular y ejecutar otras actividades del cerebro, particularmente, la manipulación de la información de acuerdo con las leyes de la lógica matemática. "La necesidad de 'moler números' aceleró el desarrollo del computador electrónico" (Bell, 1984, p. 27).

De acuerdo con Coello (2003), el desarrollo de los ordenadores ha tenido tres periodos: El primero, desde la difusión de los planos hasta 1951, caracterizado por la construcción de ordenadores en las universidades. El segundo (1951-1959) es marcado porque deja de ser el ordenador una máquina de uso exclusivo de las universidades para convertirse en un producto de comercialización. El tercero comienza en la década de los sesenta con la utilización del transistor, logro de la física cuántica caracterizado por las innovaciones de tipo electrónico, microelectrónico y, actualmente, nanotecnológico.

El progreso de la teoría física, la matemática y la tecnología da pie a la concepción de la cibernética de segundo orden, la cual "se ocupa del estudio de sistemas con causalidad circular que operan con base en autorreferencia" (Aguado, 2005, p. 204). La cibernética de primer orden se convierte en cibernética de segundo orden cuando desarrolla sistemas capaces de observar (Luhmann, 2007). La cibernética de segundo orden, según Aguado (2010), concreta un modelo epistémico en el que el mismo observador está inserto en el sistema. De este modo, el observador considera alcances, objetivos y su propio rol, en el acto de su misma concepción. Esto permite comprender la relación entre la cibernética de segundo orden y el llamado constructivismo:

¿Cómo se reconoce a un constructivista? Muy fácilmente. Si ustedes le preguntaran a uno de 
ellos si algo, digamos, una fórmula, una noción, un objeto, el orden, la simetría, una taxonomía, las leyes de la naturaleza, etcétera, se descubrió o se inventó, un constructivista tendería a decir que se inventó. Más aún, si se lo presiona fuertemente, un constructivista diría incluso que el mundo tal como lo conocemos es nuestra invención. Desde el momento en que cualquier cosa que inventamos es de nuestra responsabilidad, la posición constructivista contiene la semilla de la ética. (Foerster, 2006, p. 126).

La cibernética de segundo orden ve la sociedad como un sistema que necesita un lenguaje común en el proceso de retroalimentación con el mundo exterior. Es decir, de la misma manera como funciona la máquina universal de Turing, en la cual no se puede dar una regulación si no hay un lenguaje, se debe dar un orden sistémico social, que estará mediado por la efectividad regulativa de la comunicación que se efectúa entre el sujeto y su entorno (Watzlawick y Nardone, 2014). De ahí que para Foerster (1998) la cibernética, en virtud de su principio de autoorganización, se puede aplicar al campo socioadministrativo a partir de procesos lingüísticos y de manera análoga a los sistemas sociales y culturales. Es así como la cibernética de segundo orden trata de mediar en los procesos comunicativos, teniendo como actor al sujeto en un escenario macro. En este marco, lo sistémico social se convierte performativo, a partir de la correspondencia matemática binaria input/output (entrada/salida). Estas relaciones performativas también pueden verse en una escala micro, por ejemplo, en el de autoorganización y funcionalidad conservativa de las células (Churchland, 1992). Desde esta perspectiva, el sistema nervioso, que está conformado por gran cantidad de células, sería comprendido como un proceso cuantificable que conduce a un ordenamiento de tipo lógico, capaz de recibir información y procesarla para tomar una decisión ante un determinado efecto (Sloman, 2003).

Desde la cibernética de segundo orden, la pregunta "qué se conoce" pasa a un segundo plano, pues, al ser el conocimiento dependiente del observador, comienza a cobrar vigencia la pregunta "cómo se conoce" (Foerster, 1981), cómo conoce el sujeto cibernético. Esta pregunta viene acompañada del interés de subjetivar un nuevo hombre: el avatar; y una nueva sociedad: la sociedad de control.

En síntesis, las necesidades militares y logísticas que surgieron con la Segunda Guerra Mundial configuraron principalmente las teorías que permitirían estructurar una nueva realidad: la realidad cibernética. Esta funge como el resultado de una comprensión ontológica basada en los siguientes elementos: a) lo real es información; b) la información es traducible a códigos matemáticos, especialmente a códigos probabilísticos; c) los avances sociales, culturales y científicos están atados a las nuevas tecnologías de la información. Afirman Farias y Ossandon (2006) que en la era cibernética se ambicionan una nueva comprensión de la realidad que permita comprender los procesos cognoscitivos de la mente y crear sistemas de control para el manejo de la sociedad. Ambiciones que están asociadas a los avances científicos de punta, especialmente en los terrenos de la cibernética, la teoría de la información, la inteligencia artificial (González y Maass, 2007).

\section{El avatar como subjetividad que se constituye en la sociedad cibernética}

El propósito de este apartado es, por un lado, analizar los aspectos fundamentales que caracterizan al avatar y, por otro, presentar la sociedad de control como el modo de ser cibernético.

La sociedad del avatar se caracteriza porque está basada en las modulaciones de la información que pueden ser traducidas a cifras, y que pueden ser operadas por dispositivos tecnológicos. Es decir, esta sociedad opera "mediante máquinas de un tercer tipo, máquinas informáticas y ordenadores cuyo riesgo pasivo son las interferencias y cuyo riesgo activo son la piratería y la inoculación de virus" (Deleuze, 1999, p. 283). Advierte Deleuze que en esta sociedad, "la formación permanente tiende a sustituir la escuela, y el control continuo tiende a sustituir al examen" (Deleuze, 1999, p. 280). Afirma Virilio (1997), que la sociedad de posguerra está conformada por hombres y máquinas informáticas 
(avatar), las cuales podrían entrar en conflicto, porque la sociedad se ha transformado a partir de la velocidad y las nuevas tecnologías de la información y la comunicación.

En la sociedad de control se dan procesos de subjetivación cibernética, en donde el ser humano tiende a ser constituido como avatar. En este marco, el individuo es atravesado por fuerzas de saber y de poder transfiguradas en velocidad, comunicación y control. El avatar de la sociedad de control deberá estar acorde con estas fuerzas para lo cual debe convertirse en un ser cognitivo, que ya no dependerá de su cuerpo para la producción, sino que, por el contrario, debe potencializar sus funciones cerebrales hacia la programación para el consumo y el control. Como afirma Correa (2001) el avatar es un ser racional del cuello para arriba.

En la sociedad del avatar, la concepción de cerebro es fundamental. La concepción fisiológica de épocas antiguas comienza a ser desplazada por una concepción cibernética, la cual define el cerebro desde una perspectiva matemática y física. $\mathrm{Al}$ respecto, Walter plantea lo siguiente:

Se entiende por cerebro algo más que la masa gelatinosa de un gris rosado que maneja al anatomista [...]. "Telar encantado" lo llamó un gran fisiólogo. Otro lo ha comparado a un lago tranquilo, en el que sistemas de ondas tejen tramas. La primera imagen es un recordatorio de que lo mágico puede tener un sustrato físico. La segunda nos invita a navegar sobre la superficie de algo que es más profundo de lo que sabemos, y en donde pueden desatarse tormentas. (Walter, 1953, p. 17).

En la sociedad industrial, en donde el telar era visto como la máquina emblemática, la concepción fisiológica mecanicista del cerebro fue hegemónica. Sin embargo, esta concepción comienza a perder estatus en la sociedad de control, en la cual el cerebro es comparado con un ordenador que procesa información, funciona con energía y puede ser modelizado mediante análisis matemáticos y físicos (Cuartas, 2007). Esta concepción sirve para fundamentar la analogía comportamental entre sujetos humanos y ordenadores artificiales. El cerebro, entonces, puede entenderse como un sistema complejo que permite emitir y transmitir impulsos eléctricos codificables como información, y procesables y cuantificables como comunicación. Así, el cerebro es visto como un sistema con entradas (input) y salidas (output) manifestadas en interrelaciones neuronales que dan paso a la consolidación de impulsos eléctricos, condensando y emitiendo información a diversos organismos de forma coordinada y procedimental en la consecución de señales con diversas variaciones (Greenfield, 2012).

En concordancia con lo anterior, las investigaciones de corte cibernético sobre la complejidad del funcionamiento del sistema nervioso parten de la premisa que existe un parecido razonable entre máquina y cerebro. Teniendo en cuenta que "la observación más inmediata con respecto al sistema nervioso es que su funcionamiento es, prima facie, digital" (Von Neumann, 1958, p. 76). Esta concepción de funcionamiento digital del sistema nervioso sugiere una analogía con la cual es posible comprender al cerebro y al ordenador como "máquinas pensantes”. Según Hubel,

Si suponemos que tanto el cerebro como la computadora son máquinas, ¿ cómo hemos de compararlos? El ejercicio es interesante. Las computadoras han sido inventadas por el hombre, quien, por tanto, las comprende enteramente, si puede decirse que los seres humanos comprenden algo; lo que no saben es cómo serán las computadoras del futuro. El cerebro fue creado por evolución, y permanece sin conocerse desde muchos puntos de vista importantes. Ambas máquinas procesan información y las dos trabajan con señales que podemos calificar, en primera aproximación, de eléctricas. (1980, p. 12).

Este es el contexto de la sociedad de control, en medio de la cual las relaciones sociales están condicionadas por los flujos de información. En este tipo de sociedad, el sujeto, según Deleuze (1999), constantemente está actualizando su información y la forma de actividad e interacción con los demás siempre estará mediada por internet o por dispositivos similares: 
El homo comunicans es un ser sin interioridad y sin cuerpo que vive en una sociedad que no tiene secretos, un ser por entero volcado hacia lo social, que solo existe a través de la información y el intercambio, en una sociedad transparente gracias a las nuevas máquinas de comunicar. (Breton, 2000, p. 52).

En la sociedad de control, las subjetividades avatar y los cuerpos se ven afectados por las tecnologías de la virtualidad (Sibilia, 2009). El desarrollo del hombre depende de esa capacidad de usar todas las formas posibles de comunicarse. Su interioridad ya no depende de sí mismo, sino del gran flujo de información. Todo lo interno se exterioriza, se vuelve transparente:

El hombre nuevo que surge de los escombros de mediados del siglo $\mathrm{xx}$ es una especie de antítesis, un hombre dirigido desde el exterior. Saca su energía y su sustancia vital no de cualidades intrínsecas que provendrían del fondo de sí mismo, sino de su capacidad como individuo conectado, conectado a vastos sistemas de comunicación, para recoger, tratar, analizar la información que necesita para vivir. (Breton, 1997, 57).

Así, el hombre ya no actúa desde una necesidad interna. Ya no es esa búsqueda de lo que siente necesario para ser él mismo, sino que su identidad depende de la correspondencia que haya con los códigos simbólicos que lleva la información (Soto, 2013). Su existencia está mediada con la conexión directa entre el cerebro y el ordenador, su capacidad comunicativa es la que ahora determina el nivel de inteligencia.

La sociedad de control ya no actúa en los cuerpos, sino en el cerebro de los sujetos. El cuerpo se torna obsoleto, pues la interacción con las máquinas de la información no fortalece de forma alguna el sistema muscular ni desarrolla algún tipo de destreza física (Breton, 1989). Como señala Dery (2002), el cuerpo nuevamente es rechazado en cuanto es perecedero, solo la mente es la que hace posible el acoplarse a la velocidad vertiginosa de la comunicación. Dada su condición ontológica cuantitativa, la sociedad de control no deja lugar a las diferencias cualitativas, como las que se dan entre el avatar y la persona humana.
En resumen, la comprensión ontológica de la realidad como información cuantificable, que puede ser descifrada y transformada mediante las nuevas tecnologías de la información (véase "La física azarosa como el modo de ontología que adopta la cibernética"), implica un modo de subjetivación del hombre como avatar y una concepción de la sociedad cibernética como sociedad de control. El hombre avatar se caracteriza, especialmente, por desarrollar un cerebro capaz de procesar información, la cual es traducible al lenguaje de la matemática probabilística e intercambiable con las máquinas que proveen las nuevas tecnologías de la información y la comunicación. La sociedad de control, por su parte, se caracteriza por ser una sociedad transparente en la que las relaciones entre procesadores cognitivos, ya sean hombres o máquinas, están condicionadas por el control, la actualidad, la velocidad y la comunicación de los flujos de información. En la sociedad de control, que opera con una ontología de la factualidad, el hombre avatar no funge como un ser singular e interior, sino como un ser lógico y exterior, homologable a un procesador de información.

\section{El avatar como modo de ser cuantitativo y estacionario}

Los dos apartados anteriores prestan las bases para comprender el avatar como el modo de subjetivación con el que opera la cibernética. Ahora bien, para comprender los alcances y límites de esta subjetivación, conviene explicitar antes los supuestos ontológicos que subyacen en esta perspectiva.

La ontología es el estudio de lo que hay (Quine, 1948). ¿Qué hay según la cibernética? Para este modo de investigar lo que hay en el mundo es información (Breton, 2000). El mundo puede ser entendido, descifrado y reconstruido como un sistema de códigos de información (Aguilar, 2008). Esta información se caracteriza por ser traducible al lenguaje de la física matemática (Fodor, 1993). Por ejemplo, la información del código genético de la vida es traducible al código binario de las matemáticas. En este marco, las tecnologías de la información desempeñan un papel fundamental, ya que 
ellas, según Haraway (1995), fungen como la interfaz entre el hombre obsoleto y la máquina perfeccionada. Dicha interfaz no opera neutralmente, sino que está llamada a inaugurar una era poshumana, cuyo desarrollo superaría problemas arcaicos como los de etnia, género, clase, diferencia, identidad, entre otros (Gray, 2001).

En este sentido, la cibernética opera con una ontología naturalista y funcionalista que define y organiza lo que hay en estrecha relación con la información, o con los sistemas que esta posibilita. De ahí que los sistemas de información con los que opera la cibernética constituyan relaciones que pueden ser expresadas mediante ceros y unos, vehiculadas a través tecnologías sofisticadas y reguladas mediante leyes físico-matemáticas. Es decir, la investigación cibernética problematiza lo real en cuanto espacio natural o físico representable en descripciones y explicaciones de hechos informativos que pueden ser analizados, prescritos y anticipados a partir de procedimientos tecnológicos y científicos objetivos. La concepción ontológica de lo que hay en cuanto información cuantificable puede ser denominada ontología de la factualidad (Sáez, 2002, p. 17). Esta ontología procura la naturalización de la información y del significado haciendo recurso a una analogía fundamental: realidad/información/matemática. Así, lo factual puede ser entendido como la información susceptible de ser representada como facta, esto es, como estados de cosas o datos cuantificables.

En síntesis, podemos afirmar que la cibernética se caracteriza por dos rasgos fundamentales: una ontología de la factualidad y un saber físico que privilegia la objetividad cuantitativa. Ahora bien, ¿cuál es la concepción de hombre que se deriva de la perspectiva cibernética? La cibernética concibe al hombre como un avatar, es decir, como una información física susceptible de ser representada, explicada y regulada de forma cuantitativa: "el hombre es un ente de carácter puramente físico, una máquina bioquímica gobernada y descrita en todas sus facetas por las leyes físicas conocidas" (Tipler, 1996, p. 34). El avatar es un facta que se rige por leyes objetivas impersonales. De acuerdo con Aguilar, la cibernética "reconoce la posición del individuo como otro componente o subsistema (de información) sujeto a las leyes probabilísticas que son el modo de operación del sistema" (2008, p. 16). Así, el hombre avatar es entendido como un cybernetic organism (cyborg), esto es, un código de información que puede ser descifrado haciendo recurso de la matemática probabilística (Haraway, 1995). El hombre avatar, en cuanto código de información, comparte su estructura con la vida natural (código genético) y con la máquina (código binario). El animal, el hombre y la máquina son comprendidos por la cibernética como procesadores de información que guardan una diferencia cuantitativa, pero no una diferencia cualitativa. Al respecto, Aguilar, afirma que, según la cibernética, "somos información, la base biológica que se revelaba como un sustrato inalterable ha quedado refutada con el descubrimiento del genoma humano, que nos denuncia más como una escritura o información modificable que como carne estática” (2008, p. 16).

Consideramos que la ontología de la factualidad, con la cual opera la cibernética, no da espacio para comprender al hombre como persona, pues lo personal hace referencia a una realidad cualitativa que difiere ontológicamente de la realidad cuantitativa (Villamil, 2012). De ahí que consideremos que la ontología de factualidad resulta insuficiente. Ahora bien, si tal ontología se plantea como la ontología y no como una ontología, entonces, además de insuficiente, resulta sesgada. Resulta sesgada porque deja sin consistencia ontológica una serie de fenómenos que son reales, aunque no sean cuantitativos o traducibles a facta (Sáez, 2009). Entre dichos fenómenos están aquellos que atañen al ámbito personal. Una concepción absoluta del mundo como un lugar donde solo ocurren fenómenos informáticos traducibles a datos cuantificables es deshumanizada y estacionaria. Es deshumanizada ya que vacía al mundo de los rastros y rostros humanos en beneficio de una representación impersonal, imparcial y objetiva (Stroud, 2000). Es estacionaria en la medida en que paraliza o inmoviliza el dinamismo personal de los seres humanos en medio de un espacio que solo admite códigos digitales. De ahí que frente a la ontología de la factualidad convenga desarrollar 
una ontología experiencial que permita comprender la realidad de los fenómenos personales e interpersonales en el mundo de la vida (Gallagher y Zahavi, 2014; Sáez, 2002).

Lo personal hace referencia a la correlación de tres aspectos fundamentales: el carácter singular de la persona humana, su carácter interpersonal y su carácter relacional con el mundo (Villamil, 2009). Lo personal no hace referencia ni a un estado de cosas, ni a un conglomerado de información cuantificable como datos, ni a hechos físicos susceptibles de ser representados como casos de una ley. Lo personal hace referencia más bien a un modo de ser que, por un lado, muestra a la persona como alguien único, irrepetible y capaz de generar su propia personalidad; $y$, por otro, como alguien social que se personaliza en estrecha relación con los otros y con el mundo (Herrera, 2003). Es decir, lo personal hace referencia a un dinamismo cualitativo que conjuga potencias problemáticas, valorativas y vocacionales (Villamil, 2017). Veamos en qué consisten estas tres potencias y el rol que cumplen en dicho dinamismo cualitativo.

Lo personal, en primer lugar, hace referencia a la potencia problemática del mundo. El mundo que habitan las personas se muestra como un flujo de problemas que interpelan a las personas por respuestas que sintonicen tanto con las situaciones inquietantes, como con la repercusión de estas en los proyectos personales (Sáez, 2015, pp. 15-20). Este punto de vista contrasta con el enfoque de la ontología de la factualidad, desde el cual se comprende el mundo no como un campo de juego problemático que apela por respuestas más o menos satisfactorias, sino como un flujo de información que entraña una objetividad desconocida que hay que descubrir. En esta ontología factual las respuestas no son descritas como resoluciones personales de problemas valorativos que acontecen en el mundo, sino como constataciones de hechos sucedidos o como predicciones objetivas de estados posibles.

La comprensión del mundo como un ámbito problemático abre un campo de juego interpersonal y público (Luypen, 1967; Solomon, 2008) en donde, por un lado, acontecen relaciones diferenciales e inquietantes entre modos de ser heterogéneos (personas, animales, cosas, textos, símbolos, etc.) y, por otro, en donde surgen las respuestas personales correlativas con lo importante y con los proyectos de vida propios. Es decir, en este campo de juego las experiencias personales surgen como acontecimientos que ligan a las personas con problemáticas valorativas que suceden en el mundo; y también como movimientos comprensivos y responsivos que abren sendas de realización ligadas con los proyectos de personalidad. La captación de este dinamismo problemático y responsivo nos brinda las bases para explicitar las experiencias personales como modos de ser que comportan movimientos de inserción ligados con dramas problemáticos y movimientos erráticos abiertos a realizaciones inéditas y mejores. Así, la perspectiva experiencial desarrolla una ontología dinámica que permite captar la manera como las personas se las ingenian para comprender las problemáticas que devienen de la relación inquietante con lo importante en el mundo y para responder estas problemáticas en sintonía con el llegar a ser de personalidades singulares.

Lo personal, en segundo lugar, hace referencia a la potencia valorativa. Esta potencia se muestra como un dinamismo cualitativo que, instigado por el movimiento problemático del mundo, pone en obra dos movimientos esenciales, a saber: el que responde a las problemáticas más o menos relevantes para el bienestar de las personas, y el que liga las problemáticas y las respuestas con el proyecto de vida que la persona valora como bueno (Lazarus, 2000, p. 44). La problemática importante propicia un juego de ida $y$ vuelta en el que la persona experimenta no una pasión estática y transparente, sino una apelación dinámica que debe ser respondida en sintonía con la valoración del bienestar y con la valoración de la vida buena en un mundo mejor. De este modo, la apelación que inquieta el estar de la persona en el mundo puede ser vista como una tensión valorativa que promueve unas respuestas más o menos acordes con la problemática, más o menos acordes con el bienestar de la persona, y más o menos acordes con la vida buena de las personas. De esta forma, las valoraciones pueden ser mostradas como los 
movimientos que dinamizan el preferir y el postergar de las personas en beneficio de sus proyectos de vida buena en un mundo de la vida mejor (Fernández, 2012). El posicionamiento valorativo de la persona en el mundo abre un proyecto de ser singular (Conill, 2010), que tiene que ingeniárselas para sortear las problemáticas y conquistar el bienestar y el llegar a ser de su personalidad.

Lazarus (2000) capta lo importante que caracteriza las experiencias personales no como información neutral, sino como valoraciones con significado relacional y transaccional. En virtud de su significado relacional, la persona comprende las cualidades del mundo y la relevancia de éstas para la situación. La persona y el mundo interactúan, pero es la persona quien valora la situación y la relación de esta con su bienestar. En virtud de su significado transaccional, la persona relaciona el sentido de lo relevante con un dinamismo allende la acción, con una trans-acción, esto es, con una articulación entre la acción y la proyección de los planes y los objetivos personales: "la relevancia del objetivo es fundamental para que una transacción sea considerada por la persona como relevante para su bienestar" (p. 103). El significado valorativo de las experiencias personales descrito por Lazarus puede ser comprendido como el dinamismo que compromete la valoración de lo importante en el mundo con el bienestar y con el proyecto de vida buena de la persona. Las experiencias personales no ocurren solo como pasiones o vivencias pasivas, sino también como apelaciones que, en su devenir problemático y responsivo, dinamizan valoraciones comprometidas con el bienestar de las personas en el mundo y también con sus aspiraciones vocacionales de vida buena.

Lo personal, en tercer lugar, hace referencia a la potencia vocacional de las personas (Sokolowsi, 2013). En este sentido, la persona se caracteriza por el posicionamiento valorativo comprometido con el llegar a ser de la personalidad. La ontología experiencial permite mostrar este posicionamiento más como la apertura hacia el cultivo de un ingenio o saber práctico valorativo, que como el operar de un patrón de respuesta vinculado a estados regidos por leyes causales o reglas racionales. Así, aporta una comprensión de la realidad que posibilita mostrar a la persona no como una información que deviene en estados cuantificables, sino como un modo de ser dinámico que experimenta acontecimientos correlativos con el mundo y con su aspiración vocacional de vida buena (Crespo, 2012; Vargas, 2007).

Desde la ontología experiencial, el acontecer de las experiencias personales puede ser captado como un dinamismo que involucra a las personas de tal forma que para ellas no cabe la actitud de indiferencia o neutralidad valorativa de un observador o espectador desinteresado. Así, admite la captación de la experiencia como la puesta en obra de un dinamismo testimonial que saca a las personas de su indiferencia y las incita a posicionarse como participantes comprensivos, valorativos y responsivos comprometidos con aquello que es relevante para sus vidas. Esta ontología permite captar el posicionamiento personal no como algo que alude a un sujeto procesador de información -pues este supone el campo de una representación que permite distinguir los sujetos y los objetos (San Martín, 2015)-, sino como un modo ser dinámico y valorativo que compromete a la persona con su vocación personal; un modo de ser que pone a la persona no solo como paciente o como agente, sino como un ser movido por un mundo problemático y moviente de respuestas valorativas comprometidas con su bienestar y con su vida buena en un mundo mejor. Así, la persona puede ser captada como un testigo, esto es, como alguien que testimonia el acontecer de las experiencias emocionales y en virtud de ellas proyecta su vocación en el mundo. La persona puede ser mostrada como un alguien cuyo compromiso comprensivo y responsivo en el mundo repercute en el llegar a ser de su vida buena.

La captación del dinamismo vocacional nos permite comprender por qué la valoración de lo importante no solo es relevante para la situación inmediata, sino también para los compromisos de esta con las expectativas de vida de la persona (Colombetti, 2010). La ontología de la factualidad que desarrolla la perspectiva cibernética es 
impersonal, ya que no permite captar este dinamismo vocacional. Este dinamismo no deviene como un estado o una sucesión de estados informativos, sino como un modo de ser dinámico y cualitativo que se despliega en un lugar distinto al que propicia la representación estática. Este modo de ser dinámico y cualitativo articula un más acá y un más allá de la experiencia concreta (Conill, 2010, Xolocotzi, 2007). El más acá hace referencia a las variables biográficas y culturales conformadoras de la vida histórica de las personas. El más allá hace referencia a la errancia hacia modos inéditos y creativos que dinamizan y promueven la realización de la vocación personal (Sáez, 2009, p. 17).

La captación del dinamismo vocacional, que liga el acontecer de las experiencias personales con este más acá y con este más allá cualitativos, permite mostrar el llegar a ser de la personalidad como la puesta en obra de un modo de ser personal abierto tanto a un horizonte de tiempo sucedido, como a un horizonte de tiempo inédito por realizar. De esta forma, la ontología experiencial posibilita comprender la vocación personal no como algo innato o adquirido mecánicamente, ni como un estado de cosas definido, sino como el ejercicio comprensivo, responsivo y proyectivo de una personalidad. Es decir, como un ejercicio de personalización dinamizado por problemáticas imprevisibles que, al apelar por una resolución novedosa, promueven la emergencia de un modo de ser singular (Sáez, 2015, p. 108; Simondon, 2009, 397).

En resumen, la ontología experiencial permite, por un lado, confrontar la ontología de la factualidad, que concibe las experiencias como estados de información cualitativamente estáticos e impersonales; $y$, por otro lado, aporta una comprensión dinámica de la realidad que admite mostrar los aspectos cualitativos que caracterizan esencialmente las experiencias personales. En este sentido, tal ontología permite explicitar lo personal como la dinámica cualitativa de las potencias problemática, valorativa y vocacional: a) el mundo se muestra como un campo de juego problemático en el que acontecen experiencias personales importantes, las cuales dinamizan comprensiones y respuestas valorativas por parte de las personas; b) las personas se muestran como seres cualitativamente dinámicos, capaces de posicionarse de manera comprensiva y responsiva frente a las problemáticas valorativas que acontecen en el mundo; y el sentido de la experiencia se muestra como el dinamismo valorativo que conjuga la valoración del mundo, la valoración del bienestar de la persona y la valoración de su proyecto de vida buena en un mundo de la vida mejor; c) la vocación personal se muestra como la puesta en obra de un modo de ser singular que se interrelaciona ingeniosa y valorativamente con el mundo y con la realización de un proyecto de vida inédito $y$ bueno en un mundo de la vida mejor.

Vista desde una perspectiva cualitativa, la postura cibernética resulta impersonal y estacionaria, puesto que el avatar y la sociedad de control no tienden a promover las potencias que caracterizan el dinamismo del modo de ser personal. De ahí que consideremos que la indagación de las problemáticas valorativas, sus correlativas respuestas personales y la relevancia de ambas en el desarrollo de la vocación, requieren una ontología distinta a la de la factualidad: requieren una ontología experiencial que le reconozca a lo personal un estatuto de realidad, significatividad, libertad, responsabilidad y creatividad (Villamil, 2017). En este sentido, la persona no debe ser comprendida simplemente como un avatar procesador de información cuantificable $y$ controlable de forma transparente, sino como un modo de ser cualitativo que con su vida puede testimoniar aventuras singulares, inéditas y creativas.

Dado lo anterior, finalmente, consideramos que el cultivo del ethos de la paz requiere de la comprensión y promoción de otras subjetividades alternas a la que se ha construido artificialmente desde la información como avatar.

\section{Referencias}

Aguado, J.M. (2005). La información como problema observacional. Cuadernos de Información y Comunicación, 10, 197-218. Recuperado de 
http://revistas.ucm.es/inf/11357991/articulos/ CIYC0505110197A.PDF

Aguado, J.M. (2010). Sistemas de medios y gestión de la identidad: Notas para una revisión de la perspectiva sistemática en comunicación de masas. En G. Abril, El cuarto bios: Estudios sobre comunicación e información (pp. 193-219). Madrid: Complutense.

Aguilar, T. (2008). Ontología cyborg. El cuerpo en la nueva sociedad tecnológica. Barcelona: Gedisa.

Bell, D. (1984). Las ciencias sociales desde la Segunda Guerra Mundial. Madrid: Alianza.

Breton, P. (1989). Historia y crítica de la informática. Madrid: Cátedra.

Breton, P. (2000). La utopía de la comunicación. El mito de la aldea global. Buenos Aires: Nueva Visión.

Buckley, W. (1993). La sociología moderna y la teoría moderna de los sistemas. Buenos Aires: Amorrortu.

Churchland, P. (1992). Materia y conciencia. Barcelona: Gedisa.

Coello, C. (2003). Breve historia de la computación y sus pioneros. México, D.F.: Fondo de Cultura Económica.

Colombetti, G. (2010). Enaction, Sense-Making and Emotion. En J. Stewart, O. Gapenne y E. Di Paolo (eds.), Enaction. Toward a New Paradigm for Cognitive Science (pp. 145-164). Cambridge: MIT Press.

Conill, J. (2010). Ética hermenéutica. Crítica desde la facticidad. Madrid: Tecnos.

Correa, D. (2001). Pensamientos de sabiduría divina y humana. Bogotá: Universidad de San Buenaventura.

Crespo, M. (2012). El valor ético de la afectividad. Estudios de ética fenomenológica. Santiago de Chile: Pontificia Universidad Católica de Chile.

Cuartas, J. (2007). Los rumbos de la mente. Bogotá: Universidad Pedagógica Nacional.

Deleuze, G. (1999). Conversaciones. Valencia: Pre-Textos.

Dery, M. (2002). Velocidad de escape. Madrid: Siruela.

Farias, I. y Ossandon, J. (2006). Observando sistemas: nuevas apropiaciones y usos de la teoría de Niklas Luhmann. Santiago de Chile: Fundación Soles.

Fernández, P. (2012). Razón afectiva y valores. Más allá del subjetivismo y el objetivismo. Anuario Filosófico. Fenomenología de las Emociones, 45(1), 33-67.

Foerster, H. (1981). Perception of the future and the future of perception. Intersystems Publications, 1(1), 31-43.
Foerster, H. (1998). Sistemas observadores. En J. Ibáñez (coord.). Nuevos avances en la investigación social I (pp. 146-153). Barcelona: Proyecto A.

Foerster, H. (2006). Las semillas de la cibernética: obras escogidas. 6a. ed. Barcelona: Gedisa.

Fodor, J. (1993). The Elm and the Expert. Cambridge: The M.I.T. Press.

Gallagher, S. y Zahavi, D. (2014). La mente fenomenológica. Madrid: Alianza.

George, F. y Johnson, L. (1985). Purposive behaviour and teleological explanations. Nueva York: Gordon and Breach Science.

Gifreu, A. (2013). Pioneros de la tecnología digital. Cataluña: UOC.

González, A. y Mass, M. (2007). Cibercultura e iniciación en la investigación. Mexico, D.F.: UNAM.

Gray, C. (2001). Cyborg Citizen. Politics in the Posthuman Age. Nueva York: Routledge.

Greenfield, S. (2012). El poder del cerebro: cómo funciona y que puede hacer la mente humana. Barcelona: Crítica.

Haraway, D. (1995). Ciencia, cyborgs y mujeres. La reinvención de la naturaleza. Madrid: Cátedra.

Heims, S. (1986). J. Von Neumann y N. Wiener. Barcelona: Salvat.

Heims, S. (1995). Introducción. En N. Wiener. Inventar: Sobre la gestación y el cultivo de las ideas (pp. 9-22). Barcelona: Tusquets.

Herrera, D. (2003). La persona y el mundo de su experiencia. Bogotá: Editorial Bonaventuriana.

Hubel, D. (1980). El cerebro. En El Cerebro (pp. 11-24). Barcelona: Labor.

Jolley, N. (2005). Leibniz. Nueva York: Routledge.

Kasner, E. y Newman, J. (2007). Matemáticas e imaginación. México, D.F.: Conaculta.

Kline, R. (2015). The cybernetics moment: or why we call our age the information age. Baltimore: Johns Hopkins University Press.

Lazarus, R. (2000). Estrés y emoción. Manejo e implicaciones en nuestra salud. Bilbao: Desclée de Brouwer.

Luhmann N. (2007). La realidad de los medios de masas. Barcelona: Anthropos.

Luypen, W. (1967). Fenomenología existencial. Buenos Aires: Carlos Lohlé.

Mattelart, A. (2002). Historia de la sociedad de la información. Barcelona: Paidós. 
Otero, E. (2004). Teorías de la comunicación. Santiago de Chile: Universitaria.

Quine, W. (1948). On what there is. Review of Metaphysics, 2(5), 21-38.

Rosenblueth, A., Wiener, N. y Bigelow. (1943). Behavior, Purpose and Teleology. Philosophy of Science, 10(1), 18-24. Recuperado de http://cleamc11.vub.ac.be/ Books/Wiener-teleology.pdf

Sáez, L. (2002). El conflicto entre analíticos y continentales. Dos tradiciones filosóficas. Barcelona: Crítica.

Sáez, L. (2009). Ser errático. Madrid: Trotta.

Sáez, L. (2015). El ocaso de Occidente. Barcelona: Herder.

San Martín, J. (2015). Antropología filosófica II. Vida humana, persona y cultura. Madrid: Universidad Nacional de Educación a Distancia.

Shannon, C. (1948). A Mathematical Theory of Communication. The Bell System Technical, 27, 379-423. Recuperado de: http://worrydream.com/ refs/Shannon \%20-\%20A\%20Mathematical\%20 Theory\%20of\%20Communication.pdf

Sibilia, P. (2009). El hombre postorgánico: cuerpo, subjetividad y tecnologías digitales. 2a. ed. Buenos Aires: Fondo de Cultura Económica.

Simondon, G. (2009). La individuación a la luz de las nociones de forma e individuación. Buenos Aires: La Cebra-Cactus.

Sloman, A. (2003). La relación conocimiento y lenguaje en la cibernética de segundo orden. Recuperado de http://www.antroposmoderno.com/antro-articulo. php?idarticulo=703

Sokolowski, R. (2013). Fenomenología de la persona humana. Salamanca: Sígueme.

Solomon, R. (2008). Ética emocional. Una teoría de los sentimientos. Barcelona: Paidós.

Soto, W. (2010). La cultura de la cibernética. Bogotá: Bonaventuriana.

Soto, W. (2013). Cibernética y pedagogía. Bogotá: Bonventuriana.
Stroud, B. (2000). The Quest for Reality. Oxford: Oxford University Press.

Tipler, F. (1996). La física de la inmortalidad. Alianza: Madrid.

Vargas, J. (2007). La ética fenomenológica de Edmund Husserl como ética de la renovación y ética personal. Estudios Filosóficos, 36, 61-93.

Villamil, M. (2009). Valores y derechos humanos. Implicaciones jurídicas y pedagógicas. Bogotá: Bonaventuriana.

Villamil, M. (2012). Qué, cómo y para qué de la fenomenología de Husserl. En: A. Rocha (ed.), Reflexiones en filosofía contemporánea (pp. 235-254). Buenos Aires: Gramma.

Villamil, M. (2017). Emociones humanas y ética: para una fenomenología de las experiencias personales erráticas. Bogotá: Pontificia Universidad Javeriana.

Virilio, P. (1997). El cibermundo: la política de lo peor. Madrid: Cátedra.

Von Neumann, J. (1958). El ordenador y el cerebro. En A. Bosch (ed.), El ordenador y el cerebro (pp. 41-114). Barcelona: Bon Ton.

Walter, G. (1953). El cerebro viviente. 2a. ed. México: Fondo de Cultura Económica.

Watzlawick, P. y Nardone, G. (2014). Terapia breve estratégica: Pasos hacia un cambio de percepción de la realidad. Barcelona: Paidós.

Wiener, N. (1956). I Am a Mathematician: The later Life of a prodigy. Garden City, Nueva York: Doubleday.

Wiener, N. (1958). Cibernética y sociedad. Buenos Aires: Sudamericana.

Wiener, N. (1998). Cibernética o el control y la comunicación en animales y máquinas. 2a. ed. Barcelona: Tusquets.

Xolocotzi, A. (2007). Subjetividad radical y comprensión afectiva. El rompimiento de la representación en Rickert, Dilthey, Husserl y Heidegger. México: Plaza y Valdés. 